\title{
Pseudoaneurysm of the Petrosal Internal Carotid Artery in the Middle Ear as a Complication of Middle Ear Cholesteatoma
}

\author{
Seung Hyo Choi ${ }^{1}$, Hyun Park ${ }^{2}$, Tae Ki Yang ${ }^{3}$, and Chan II Song ${ }^{1}$ \\ ${ }^{1}$ Departments of Otorhinolaryngology-Head and Neck Surgery, ${ }^{3}$ Neurosurgery, Jeju National University Hospital, Jeju, \\ ${ }^{2}$ Department of Neurosurgery, Gyeongsang National University Hospital, Jinju, Korea
}

$\begin{array}{ll}\text { Received } & \text { December 9, 2014 } \\ \text { Revised } & \text { February 5, 2015 } \\ \text { Accepted } & \text { March 27, 2015 }\end{array}$

Address for correspondence Chan Il Song, MD

Department of OtorhinolaryngologyHead and Neck Surgery,

Jeju National University Hospital,

15 Aran 13-gil, Jeju 690-767, Korea

Tel +82-64-717-2108

Fax +82-64-717-1097

E-mail songchanil@gmail.com
We report the case of a 66-year-old man who had significant otorrhagia caused by a ruptured pseudoaneurysm in the petrous internal carotid artery (ICA). The patient had middle ear cholesteatoma, and computed tomography (CT) showed bony erosion and exposure of the ICA into the middle ear cavity. Further angiography of the right carotid artery revealed a pseudoaneurysm protruding from the petrosal ICA into the middle ear cavity. The pseudoaneurysm was promptly treated with coil embolization and stenting. The patient continues to be monitored regularly with clinical follow-up, and carotid angiography and temporal bone CT revealed no interval changes at the embolized site 3 years after the procedure.

J Audiol Otol 2015;19(1):58-61

KEY WORDS: Pseudoaneurysm · Internal carotid artery · Middle ear · Cholesteatoma

\section{Introduction}

Pseudoaneurysms of the petrous internal carotid artery (ICA) are uncommon, but have been known to result from head trauma, radiation therapy, surgical complications, tumor invasion, fibromuscular disease, or chronic otitis media [1-8]. Nevertheless, pseudoaneurysms of the petrous ICA caused by middle ear cholesteatoma are very rare. Presenting symptoms can be varied and include hearing loss, tinnitus, and life-threatening hemorrhages [9]. Therapies described to treat pseudoaneurysms in this area include coiling, stenting, and carotid sacrifice [10-12], however, due to the location of the pseudoaneurysms, and possible risk of infection, these pseudoaneurysms can be particularly difficult to treat. We treated a rare case of a successful coil embolization and stenting procedure for a pseudoaneurysm of the petrous ICA caused by middle ear cholesteatoma.

This is an Open Access article distributed under the terms of the Creative Commons Attribution Non-Commercial License (http://creativecommons. org/licenses/by-nc/3.0/) which permits unrestricted non-commercial use, distribution, and reproduction in any medium, provided the original work is properly cited.

\section{Case Report}

A 66-year-old man with a history of liver cirrhosis and middle ear cholesteatoma of the right ear presented with bleeding from the right ear. The patient had experienced significant otorrhagia 2 days prior that ceased spontaneously. There was no patient-reported history of ear-picking or other history that might have caused trauma to the middle ear. The patient had a history of episodic otorrhea from the right ear with middle ear cholesteatoma, and he had been managed conservatively for several years, as his general condition had not previously presented indications for surgery. He had the mixed hearing loss bilaterally (Fig. 1) and the air caloric test showed the right canal paresis of $54.8 \%$ weakness. A computed tomography (CT) scan showed evidence of middle ear cholesteatoma eroding the right petrous bone and extending to the cochlea (Fig. 2). In addition, brain magnetic resonance image and carotid magnetic resonance angiography revealed a small pseudoaneurysmal lesion originating from bone dehiscence of the posterior wall of the right petrous ICA segment (Fig. 3). The middle ear cholesteatoma was clinical diagnosis and a biopsy was not taken. However, there were no sign of an enhanced tumor in imaging studies. In routine follow-up tests 
Fig. 1. Pure tone audiometry before the rupture of internal carotid artery pseudoaneurysm. The patient had bilateral mixed hearing loss.

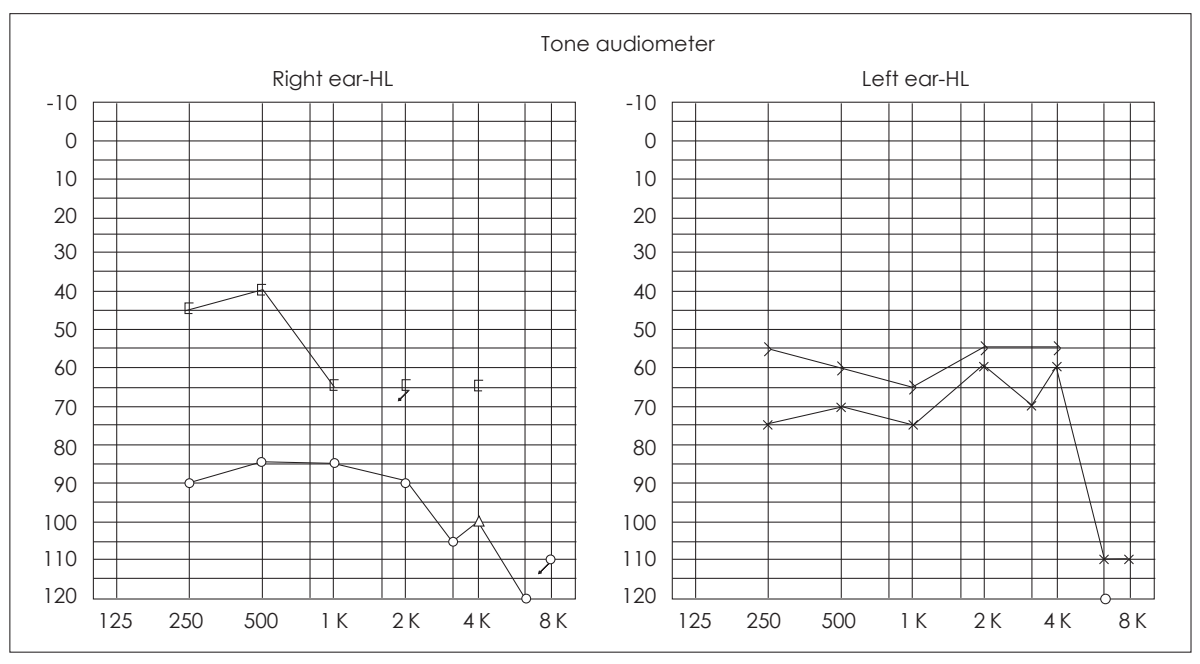

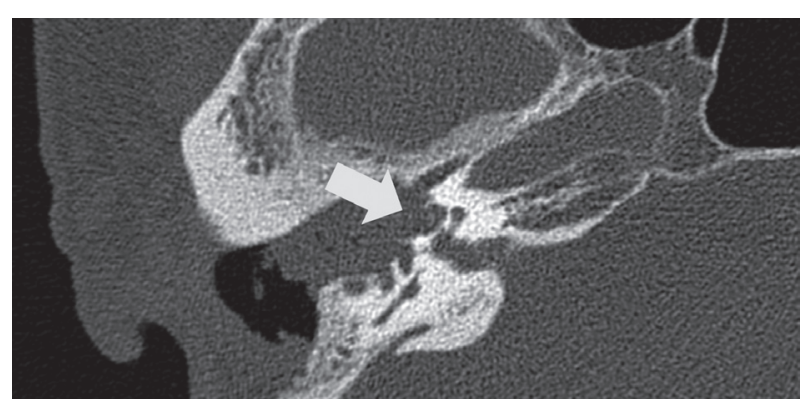

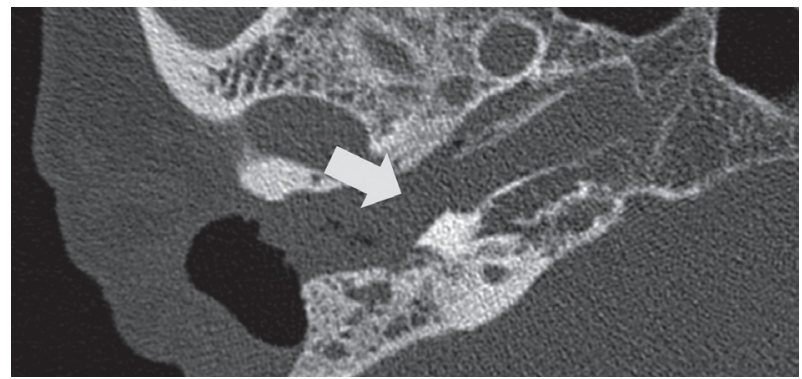

Fig. 2. Computed tomography scan of the right temporal bone, axial view. Middle ear cholesteatoma eroding the right petrous bone including the cochlea (arrows).

due to liver cirrhosis, hemoglobin $(\mathrm{Hb})$ level was over $11 \mathrm{~g} / \mathrm{dL}$, however, $\mathrm{Hb}$ of the patient was $7.6 \mathrm{~g} / \mathrm{dL}$ when he visited the emergency room.

Without further delay, a conventional angiography procedure was performed whereby a 7-F guide catheter was placed at the right proximal ICA via the femoral artery. The pseudoaneurysm measured approximately $3.8 \times 2.1 \mathrm{~mm}$. Target detachable coil ( $2 \mathrm{~mm} \times 6 \mathrm{~cm}$, Stryker, Kalamazoo, MI, USA) embolization of the pseudoaneurysm was then performed, and a Solitaire 6-20 stent (Covidien, Irvine, CA, USA) was deployed (Fig. 4). There were no postoperative complications. The patient remained stable and was discharged 1 week after the procedure.

As the tympanic membrane was perforated completely, the

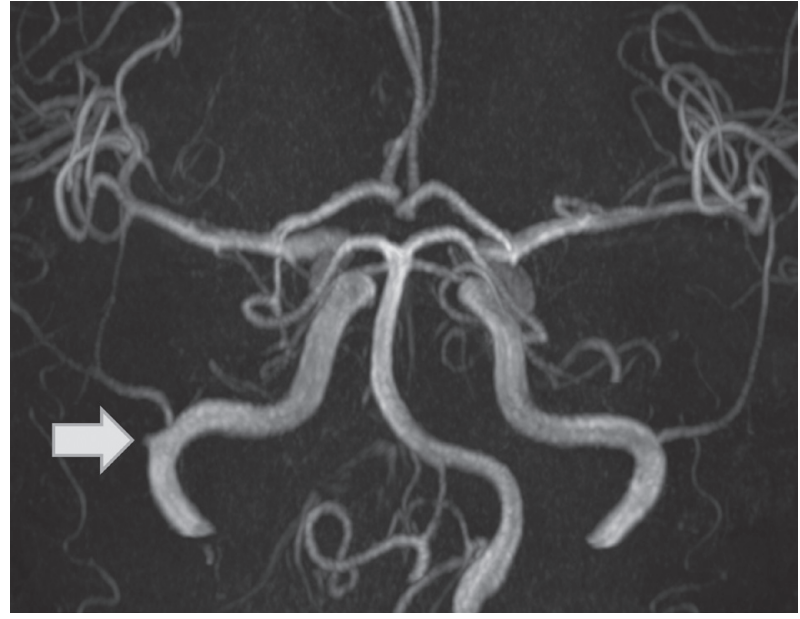

Fig. 3. Brain magnetic resonance image with carotid magnetic resonance angiography. Small pseudoaneurysmal lesion originating from bone dehiscence of posterior wall of right petrous segment ICA (arrow). ICA: internal carotid artery.

coil and pulsating ICA continued to be observed by using an ototelescope for 3 years (Fig. 5). Follow-up temporal bone $\mathrm{CT}$ and 4-vessels transfemoral carotid angiography (TFCA) showed no sign of vascular abnormalities or significant interval changes at the embolized site 3 years after the procedure. In addition, there were no reports of any episodic otorrhagia.

\section{Discussion}

A pseudoaneurysm is a blood-filled pseudovascular space contiguous to a vessel, the wall of which is formed after an artery is injured. In a true aneurysm, the vessel is enlarged, but the enlargement does not result from an injury and blood flows normally through the aneurysm. Although pseudoaneurysms of the petrous ICA have a number of different etiologies, this is the first report of a pseudoaneurysm caused by middle ear cholesteatoma. Cervical-petrous ICA aneurysms 
with a history of chronic otitis media have been reported previously $[6,13]$; however, a history of ear-pick trauma was reported in one case, and in the other case, iatrogenic injury cannot be ruled out owing to a history of tympanoplasty. We believe that, our patient was the first to present with spontaneous massive ear hemorrhage as a chief complaint. In addition, we report no evidence of recurrent complications after the procedure and during several years of follow-up.

Petrous ICA pseudoaneurysms can manifest in a variety of different ways, including pulsatile tinnitus, hearing disturbance, epistaxis, otorrhagia, and pain related to Eustachian tube blockage, as well as disturbances in cranial nerves. In addition, pseudoaneurysms are sometimes discovered as a middle ear mass during otoscopic examination [2,4-6,8]. Bleeding from the nose or ear is a particularly rare symptom; howev-

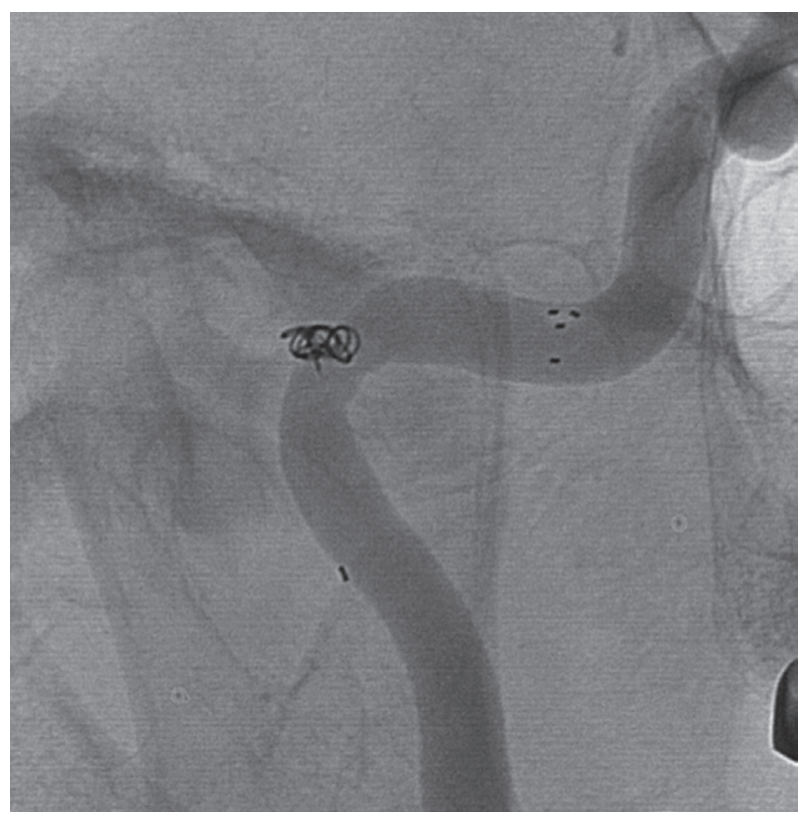

Fig. 4. Angiogram of the right internal carotid artery. Coil embolization of the pseudoaneurysm and successfully deployed endovascular stent. er, in the present case, we report massive bleeding from the ear that required immediate management as one of the first symptoms. In cases of massive otorrhagia or epistaxis, direct compression may not be suitable to stop bleeding, and aspiration of epistaxis can induce apnea and a critical state following hemorrhagic shock or respiratory failure.

Several surgical and endovascular procedures have been used to treat petrous ICA pseudoaneurysms. Nevertheless, the most appropriate management strategy for these lesions is unclear at present $[3,7]$. Surgical clipping is not utilized owing to difficulties with accessibility within the petrous bone. On the other hand, ICA occlusion with a surgical or endovascular technique is a more suitable option in the event of a lifethreatening hemorrhage, and when all other methods have failed [14]. Endovascular techniques include balloon embolization, coil embolization, stand-alone stenting, and stent-assisted coiling $[1,4,8,10,15]$. Some authors did not select coil embolization of the pseudoaneurysm due to the risks associated with depositing foreign material in the infected middle ear. Instead, revascularization by external carotid artery-middle cerebral artery bypass surgery using a vein graft is performed in order to provide immediate restoration of high blood flow and to reduce the risk of morbidity and mortality caused by acute ischemic complications [6]. This procedure, however, takes several hours to perform, and requires that the patient be placed under general anesthesia.

In the present case, we decided on an endovascular technique as the appropriate treatment option. Although our patient had a history of episodic otorrhea, we selected the stentassisted coil embolization technique because the patient had been managed regularly at the clinic for several years and his middle ear cavity was dry during recent visits. However, it should be noted that the treatment of infected pseudoaneurysms with a stent can pose risks owing to infection. Surgical treatment of radical mastoidectomy for infection control and revascularization by external carotid artery-middle cerebral

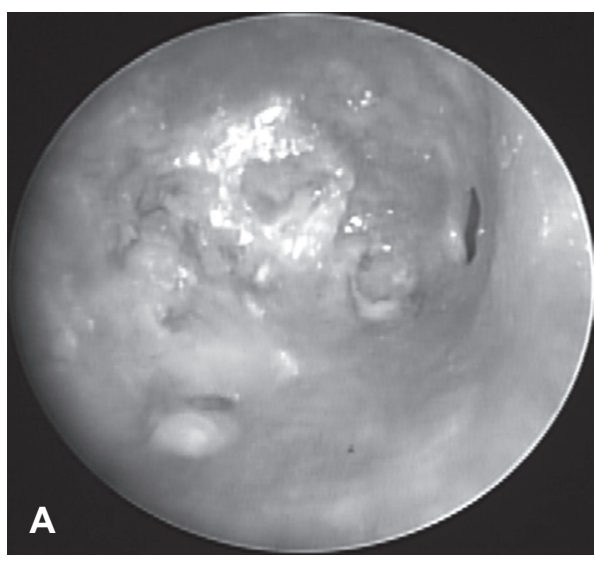

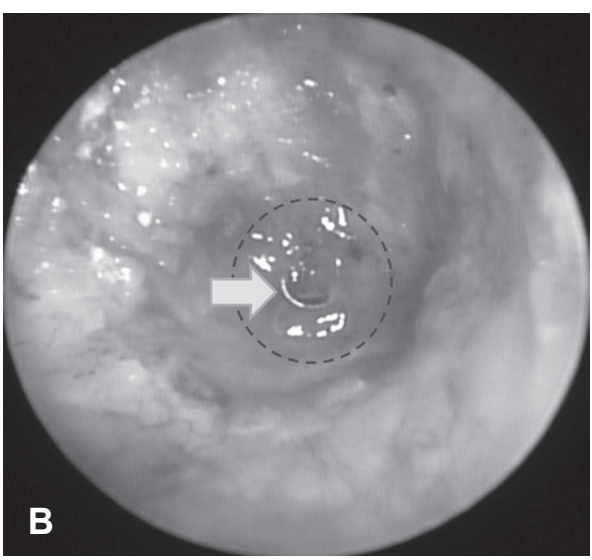

Fig. 5. Tympanic membrane before the rupture of pseudoaneurysm (A) and middle ear cavity 3 years after the coil embolization and the stent deployment (B). Coil (arrow) and pulsating internal carotid artery (dashed line) observed by ototelescope. 
artery bypass using a vein graft was considered as a radical therapy. Since the patient had severe liver cirrhosis and poor general condition, the risk of surgery exceeded that of infection and re-bleeding. The patient has undergone temporal bone CT scans for two times and TFCA once for 3 years, and he is visiting the clinic every two weeks for a otologic check-up.

In our experience, despite careful infection control and routine follow-up procedures, petrous ICA pseudoaneurysms can cause massive bleeding, and as such, prompt and early management is imperative when a petrous ICA pseudoaneurysm is identified.

\section{REFERENCES}

1) Auyeung KM, Lui WM, Chow LC, Chan FL. Massive epistaxis related to petrous carotid artery pseudoaneurysm after radiation therapy: emergency treatment with covered stent in two cases. AJNR Am J Neuroradiol 2003;24:1449-52.

2) Halbach VV, Higashida RT, Hieshima GB, Dowd CF, Barnwell SL, Edwards MS, et al. Aneurysms of the petrous portion of the internal carotid artery: results of treatment with endovascular or surgical occlusion. AJNR Am J Neuroradiol 1990;11:253-7.

3) Henriksen SD, Kindt MW, Pedersen CB, Nepper-Rasmussen HJ. Pseudoaneurysm of a lateral internal carotid artery in the middle ear. Int J Pediatr Otorhinolaryngol 2000;52:163-7.

4) Kawakami K, Kayama T, Kondo R, Kureyama H, Maruya J, Nakai O, et al. [A case of mycotic ICA petrous portion aneurysm treated with endovascular surgery]. No Shinkei Geka 1996;24:253-7.

5) McGrail KM, Heros RC, Debrun G, Beyerl BD. Aneurysm of the ICA petrous segment treated by balloon entrapment after EC-IC bypass. Case report. J Neurosurg 1986;65:249-52.
6) Oyama H, Hattori K, Tanahashi S, Kito A, Maki H, Tanahashi K. Ruptured pseudoaneurysm of the petrous internal carotid artery caused by chronic otitis media. Neurol Med Chir (Tokyo) 2010;50:578-80.

7) Rostomily RC, Newell DW, Grady MS, Wallace S, Nicholls S, Winn HR. Gunshot wounds of the internal carotid artery at the skull base: management with vein bypass grafts and a review of the literature. $\mathrm{J}$ Trauma 1997;42:123-32.

8) Willinsky R, Lasjaunias P, Pruvost P, Boucherat M. Petrous internal carotid aneurysm causing epistaxis: balloon embolization with preservation of the parent vessel. Neuroradiology 1987;29:570-2.

9) Luo CB, Teng MM, Chang FC, Chang CY, Guo WY. Radiation carotid blowout syndrome in nasopharyngeal carcinoma: angiographic features and endovascular management. Otolaryngol Head Neck Surg 2008;138:86-91.

10) Alexander MJ, Smith TP, Tucci DL. Treatment of an iatrogenic petrous carotid artery pseudoaneurysm with a Symbiot covered stent: technical case report. Neurosurgery 2002;50:658-62.

11) Barr JD, Lemley TJ. Endovascular arterial occlusion accomplished using microcoils deployed with and without proximal flow arrest: results in 19 patients. AJNR Am J Neuroradiol 1999;20:1452-6.

12) Saatci I, Cekirge HS, Ozturk MH, Arat A, Ergungor F, Sekerci Z, et al. Treatment of internal carotid artery aneurysms with a covered stent: experience in 24 patients with mid-term follow-up results. AJNR Am J Neuroradiol 2004;25:1742-9.

13) Mascitelli JR, De Leacy RA, Oermann EK, Skovrlj B, Smouha EE, Ellozy SH, et al. Cervical-petrous internal carotid artery pseudoaneurysm presenting with otorrhagia treated with endovascular techniques. J Neurointerv Surg 2014 Jul 4. pii: neurintsurg-2014-011286 [Epub ahead of print].

14) Bien AG, Cress MC, Nguyen SB, Westgate SJ, Nanda A. Endovascular treatment of a temporal bone pseudoaneurysm presenting as bloody otorrhea. J Neurol Surg Rep 2013;74:88-91.

15) Umezu H, Seki Y, Aiba T, Kumakawa K. Aneurysm arising from the petrous portion of the internal carotid artery: case report. Radiat Med 1993;11:251-5. 